\title{
How can BIM support Construction Safety Management? Development of SIM
}

\author{
Isabelle Y S Chan ${ }^{1}, \mathrm{H}$ Y Leung ${ }^{2, a}$, Ivan W H Fung ${ }^{3}$ and Michelle Leung ${ }^{1}$ \\ ${ }^{1}$ The University of Hong Kong, Pokfulam Road, Hong Kong \\ ${ }^{2}$ Nazarbayev University, Astana, Kazakhstan \\ ${ }^{2}$ City University of Hong Kong, Tat Chee Avenue, Hong Kong
}

\begin{abstract}
BIM is continuously changing the way construction can be approached, from design, scheduling, costing to facilities management. However, even though construction safety is a worldwide issue, and though previous, yet limited, studies have proven its great potential, BIM has not been extended to include automated construction safety management functions, i.e., hazard identification, assessment and control for construction works. In fact, as many as $71 \%$ of safety incidents can be prevented by safety considerations at design stage. Automation via BIM is the key to enhance effectiveness and efficiency of safety management, but development of Safety Information Modelling (SIM) is the key pre-requisite. This paper aims to outline a research project for developing both information and technical requirements for SIM via questionnaire survey, focus group, and real case studies. The project results, to be validated by real projects, will act as solid platform for developing:- i) Practical guidance to construction and safety professionals on the types of safety management a SIM can conduct, and the ways of utilizing the safety information in a SIM model [based on the systematic SIM information requirements (e.g., object identification, geometry attributes, safety rules)]; and ii) Overall guidance to software developers to develop appropriate SIM tools for different scenarios [based on the systematic SIM technical requirements (e.g., model information exchange, visualization, conflict analysis process for risk assessment, reliability)].
\end{abstract}

\section{Background}

The construction industry has long been recording the highest number of fatalities and accident rate among all industry sectors around the globe. For instance, according to the Hong Kong Census and Statistics Department in 2014, more than 3,100 construction workers have injured and 24 workers have died at work annually - that is -2 workers die every month! In fact, construction fatalities account for over $80 \%$ of the overall industrial fatalities in Hong Kong [1].

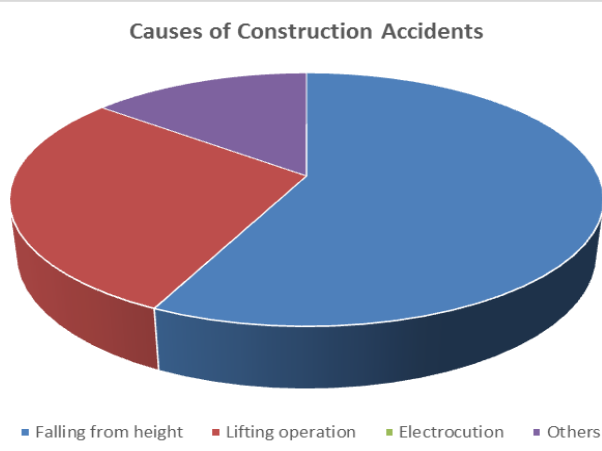

Figure 1. Causes of construction accidents [1]

\footnotetext{
${ }^{a}$ Corresponding author: hau.leung@nu.edu.kz
}

In these fatalities incidents, most of them are related to falling from height (57\%) and lifting operation (29\%) (refer to Figure 1). Moreover, the report also indicates an increasing trend of construction accidents in the past few years, increasing from 2,284 in 2010 to 3,467 in 2014 (refer to Figure 2).

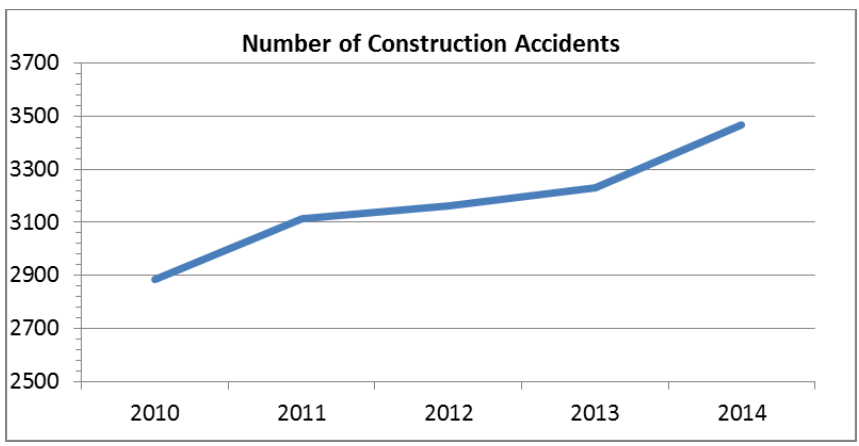

Figure 2. Number of construction accidents since 2010 [1]

It is estimated that construction safety incidents account for $6 \%$ of total building cost in general. Safety incidents not only cause serious social and economic impact to our society, but also result in significant losses to construction projects in terms of project cost and programming. In fact, various studies found that $42-71 \%$ 
of these safety incidents can actually be prevented by safety considerations at design and construction stages $[2,3]$. However, there is a lack of responsive tools to assist construction professionals to make informed decisions for construction safety.

\section{Current Practices in Construction Safety Planning, Risk and Hazards Identification}

Traditionally, safety is managed separately from construction. Safety is always considered as a hindering component to the work production and extra capital expenditure. However, construction management which focuses on productivity and fragmented from safety management tends to disregard the safety constraints within construction process and results in consistently high accident statistics. A well-integrated safety management in construction process shall be devised and put in place, otherwise, the construction project never attains the optimum benefit of the three vital objectives cost, time and quality.

Furthermore, many researchers also pointed out the lack of integration between construction process and safety issues [4-6]. Effective safety planning contributes in the prevention of accidents and ill health of site personals. Planning well for safety plays an important role in reducing unnecessary cost and delays.

In order to reduce the frequency and severity of construction accidents, construction firms implement safety programs, plans and procedures that include written safety plans [7]. Nevertheless, many constructors found difficulty in converting Safety Management Regulations [F\&IU(SM)] directive into actions and practical implementation.

Chong Pui Ho et. al. [8] conducted a research on safety planning. With approximate $5 \%$ of budget being spent on safety plan and procedures, many contractors questioned on the worthiness of spending such amounts on safety plans. The proposed research further identified the significant of assessing hazards and risks on the site. More productivity and prevention of accidents/injuries are achieved. So, it is always important to investigate possible safety issues before commencing the work on sites.

Raglan [9] revealed that many construction companies these days have a generic safety plan that is fulfilling the minimum requirement on each element on SMS. They seldom prepare a tailor-made one for each particular project and rarely have sufficient follow up action to monitor the implementation of the plan. This results to the failure in function and occurrence of accident.

In fact, safety assessment is essential as we cannot control what we did not plan for. Any unidentified hazards will not be planned for safety measures. Therefore, during the planning phase, safety must be regarded as important as construction activities [10]. Safety requirements should be the same as construction activities in work breakdown structure. A proactive safety plan and early involvement of safety in the project before hazards can be created.

Furthermore, pervious researches focus on the causes of accident, the review of construction procedures, the introduction of safety culture and the implementation of SMS. They all contribute a remarkable improvement in safety performance, but with the increase in the project's complexity and diversity, each construction site has its specific hazards and these differ from one location to another which cannot be generalized. The improvement in safety performance may reach level out nowadays and is difficult to improve further. Rajendran and Clarke [11] researched on the new methods and tools to prevent these injuries and illnesses. One such tool is BIM.

BIM is one of the most conspicuous attributes of a fundamental change that is swiftly transforming the construction industry [12-14]. A safer worksite is resulted with the improvement in communications.

\section{BIM Applications in Overseas and Hong Kong}

BIM was first incepted in the 1970s and rapidly developed in the 1980s and 1990s. It is being increasingly implemented in the construction industry to produce datarich models of buildings and structures.

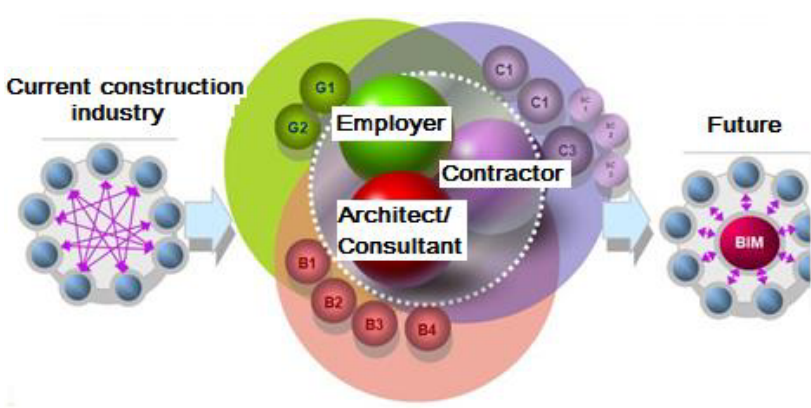

Figure 3. The change in the AEC industry after adopting a BIM approach [15]

BIM is an innovative technology that has transformed the way buildings are designed, constructed and managed. According to McGraw-Hill Construction [15], BIM is being broadly adopted across the construction industry and its use is expected to exponentially expand within forms and across the Architecture, Engineering and Construction (AEC) industry in the coming year (Figure 3). The use of BIM especially enhances the collaborative efforts of the team. The architect and engineer can test their design ideas including energy analysis. The construction manager can provide constructability, sequencing, value and engineering reports. They can also start $3 \mathrm{D}$ coordination between subcontractors and vendors during early stages of design. The owner can visually notice if the design is what he is looking for. Overall, the BIM promotes the collaboration of all of the projection participants. 
In Hong Kong, as of now BIM usage is confined mostly to the design and planning stages of the project, with very little of it being used in the construction phase. However, construction phase is well known for its roots of accidents. Furthermore, BIM technology are proved with the potential to be used in safety planning procedures particularly those related to tasks on construction sites in recent studies $[16,17]$.

Studies done by Kiviniemi [18] and Rohena [12] point out that BIM technologies are actually gradually moving from the worlds of architecture and engineering to the arenas of construction companies and other participants in the construction operations that is dramatically reshaping the ways of work in construction project teams. They also figured out the benefit of the involvement of contractor in terms of the increase in productivity and improvement of the final project outcomes for all the parties involved. The findings of studies on the use of BIM have shown that communications can be improved and errors can be eliminated; thus resulting in a safer worksite.

In fact, studies on utilizing BIM in Safety aspect in construction industry has been started in various countries recently, such as USA, Finland and Norway [19-23]. It shows that Hong Kong is lagging behind. In Hong Kong, contractors involved in the BIM are still in a limited basic and little researches on the study of construction safety in BIM are found.

In Finland, the association of Finnish Contractors is actively promoting the implementation of the BIM in the industry. VTT, one of the important organizations in the research of BIM, carried out on-going safety BIM research project from 2009 to encourage and develop utilization of BIM technology in construction planning and management - from viewpoint of occupational safety. Example are "Building Information Model (BIM) promoting safety in the construction site process" from October 2007 to February 2009 and "BIM-based Safety Management and Communication for Building Construction" from April 2009 to June 2011 which aim to develop procedures and use of BIM technology for safety planning, management, and communications, as part of the 4D-construction planning.

Moreover, the theme of the 2012's CIB W099 International Conference is "Modeling and Building Health and Safety" and it specially address the use of BIM to add the safety dimension for monitoring and improving safety performances on construction projects by launching a competition. It revealed that BIM, recognized as one of the most conspicuous attributes that is swiftly transforming the construction industry, is worth investigating and can be efficaciously enhance a safer worksite from improving the communications, eliminating errors by integrating design and collaborative features of BIM.
Nowadays, with the $4 \mathrm{D}$ scheduling platform, BIM can be used to perform design-for-safety and risk assessment, improving the inefficiencies of the paperbased processes in traditional construction safety management (i.e., text-based standalone check-sheet type tools which are conducted via paper/software interface). Although current software, e.g., Solibri, can conduct rulebased checking on BIM, it only recognizes relationships between artifacts (BIM components) and report the clashes without 'thinking' and 'analyzing' from a safety perspective. In fact, the usage of BIM in construction is still in the primary stage in Hong Kong. According to Hong Kong Construction Industry Council [24], the projects in Hong Kong are classified as 'Typical Practice' only among the five levels, namely 'Innovative Practice' (industry 'firsts'), 'Best Practice', 'Advanced Practice', 'Typical Practice' and 'Conventional Practice' (without BIM). In Hong Kong, the Hong Kong Housing Authority has long been regarded as the BIM champion driving the implementation of BIM amongst the sector. It has implemented BIM long before 2006, utilizing BIM along the whole building life cycle, from design stage, construction stage to facility management [24]. However, the implementation of BIM on construction site safety is still limited (manual safety checking based on $4 \mathrm{D}$ visualization of construction process). There is a lack of a BIM-based, automatic construction site safety management system

To automate the construction safety management process, a more comprehensive BIM has to be developed i.e., Safety Information Modelling (SIM), which includes artifacts embedded with safety-related properties or classes, with corresponding safety rules, scheduling information, geographic information, and so on. More importantly, since not all safety issues can be managed in the same way; in this project, we will investigate how SIM, with different sets of information and technical requirements, can be applied to different hazards in different construction site conditions.

\section{Development of SIM}

The concept of SIM will certainly improve and enhance the quality and efficiency of construction safety management. According to the results of the NBS National BIM Survey in 2012 [25], there are nearly $80 \%$ of construction professionals aware of and/or adopting BIM nowadays. Various professional institutions, such as the Chartered Institute of Building (CIOB) and the Royal Institution of Chartered Surveyors (RICS), have been actively involved in promoting the use of BIM among its members. However, misconceptions of BIM prevail in our industry [26], and the current adoption of BIM in our industry is still limited to the visualization level (i.e., 3D BIM). Adopting BIM in construction safety is even rarer. While the majority of construction professionals perceived that BIM can enhance quality and time of a project, nearly $50 \%$ of construction professionals fail to aware the potential of BIM on enhancing safety [27]. The limited adoption and the underestimated benefits of BIM in safety are attributed to 
the incomplete safety information available in current building information models [28,29]. Although there are limited studies investigating the utilization of rule-based hazard identification engines in certain scenarios, those studies are generally algorithm-based and case-specific, with support from limited empirical data. Those studies are hence with limited representation. In view of the above, a study is proposed to fill the gap by collecting empirical data from groups of representable safety and BIM experts to build a comprehensive platform, incorporating both information and technical requirements, for the development and implementation of SIM across different scenarios in construction projects. The research results will also be validated by real case studies using projects of our supporting organizations.

\section{Details of Proposed Research}

The research project aims to investigate the information and technical requirements for the development of Safety Information Modelling (SIM) for supporting automation of construction safety management via BIM. To achieve this aim, the objectives are:

1. To systematically review BIM in general and its application to construction safety management, in terms of design-for-safety, safety planning, risk assessment (e.g., hazard identification, assessment and control).

2. To examine the information requirements for SIM in supporting construction safety management.

3. To investigate the technical requirements for SIM based on the software tools to enhance construction safety management on site.

This empirical study will benefit not only safety professionals, but also the future development of BIM (SIM), project performance (safety) and the construction sector as a whole!

The above objectives will be realized by carrying out literature review, questionnaire survey, focus group study and real case study.

-Literature Review - A comprehensive literature review will be conducted to define and refine the research framework (e.g., BIM adoption in safety, the identified benefits and barriers, potential software tools), and to develop survey and focus group interview protocol. The review will cover both academic and professional reports, journal papers and websites.

-Questionnaire Survey - A questionnaire survey will be developed based on the extensive literature review to investigate the current BIM adoption level in different construction stages, and the anticipated critical factors and components of SIM, covering both informational and technical aspects The survey study will target construction safety professionals (say 300, incl. safety managers, safety supervisors, safety officers, assistant safety officers). The quantitative data collected will be analyzed by statistical techniques, including factor analysis, reliability analysis, Pearson correlation and multiple regression modelling, using SPSS and
Lisrel. In order to obtain high response rate, assistance may be sought from various professional bodies, e.g. CIOB, to recruit survey respondents and focus group interviewees through their membership database.

-Focus Group Study - Through providing a dynamic and interactive platform for BIM experts and construction safety professionals to exchange knowledge and demonstrate their expertise in BIM and construction safety, the focus groups will be extremely effective in helping to understand the prevailing situation, perceived benefits and barriers of SIM in construction, and to identify information and technical requirements/logics of SIM. The qualitative data collected will be analyzed by systematic contextual analysis.

- Real Case Study - The above results will be validated by real BIM projects. A number of supporting organizations have been identified and they include Institute of Safety and Health Practitioners, Chun Wo Construction Co. Ltd and Chun On Engineering Consultant Ltd.

It is anticipated that a detailed guideline and logic for implementing SIM practically [e.g., Scenario Categorization > Rule Mapping > Conflict Analysis (rule execution \& checking) > Conflict Management (report)] can be developed in this research project. The development of the new platform and all instructional guidelines of SIM should strictly refer to HK existing COPs, related safety ordinance and regulations, such as CSSR and F\&IU (Safety Management) Regulations, etc. It is also believed that the final product can be well applied in the construction industry for safety.

\section{Concluding Remarks}

BIM has been increasingly adopted in construction industry over the world, it is believed that its versatility can be readily extended to some other aspects such as construction safety management. With a view that an automated safety management system will greatly benefit the industry, a new concept of Safety Information Modelling (SIM) via the use of BIM is developed. It is anticipated that the current research project will be able to shed some light on the future development and extension of BIM to construction safety management.

\section{References}

1. Legislative Council, Legislative Council Panel on Manpower Hong Kong's Occupational Safety Performance in 2014. (2015) Retrieved from http://www.legco.gov.hk/yr14-

15/english/panels/mp/papers/mp20150616cb21683-3-e.pdf on 5th October 2015.

2. Gibb, A, Haslam, R, Hide, S and Gyi, D. The Role of Design in Accident Causality. In: $S$. Hecker, J. Gambatese and M.Weinstein, (eds) "Designing for Safety and Health in 
Construction", Eugene, Oregon: University of Oregon Press. (2004)

3. Zhou, W., Whyte, J., and Sacks, R. Building safely by design: interim report. DIRC Working Paper No. 2, Design Innovation Research Centre, University of Reading, UK. (2011)

4. Gambatese, J and Hinze, J. Addressing construction worker safety in the design phase Designing for construction worker safety, Automation in Construction, 8, 643-649. (1999)

5. Benjaoran, V., Bhokha, S.,. An integrated safety management with construction management using 4D CAD model. Safety Science 48 (3), 395-403. (2010)

6. Sulankivi, K. K., K., Mäkelä, T., Kiviniemi, M. 4D-BIM for Construction Safety Planning. $C I B$ (2010). P. Barrett, Amaratunga, Dilanthi, Haigh, Richard, Keraminiyage, Kaushal \& Pathirage, Chamind. Manchester. (2010)

7. Hallowell, M. Cost-effectiveness of construction safety programme elements, Construction Management and Economics, 28: 1, 25-34. (2010)

8. Chong Pui Ho, D., Ahemed, S. M., Chu Kwan, Jack and Wei Ming,F. Y. "Site Safety Management in Hong Kong", J. Mgmt. in Engrg, 16-34. (2000)

9. Lam, Hei-choi, Raglan, An investigation into the implementation of safety management systems by Hong Kong construction contractors. Phd. University of Hong Kong (2003). Retrieved from http://hdl.handle.net/10722/52587

10. Kartam, N.A., Integrating safety and health performance into construction CPM. Journal of Construction Engineering and Management 123, 2, 121-126. (1997)

11. Rajendran, S. and Clarke, B. Building Information Modeling: Safety benefits and opportunities. Professional Safety, October 2011, 44-51. (2011)

12. Raymond Rohena "BUILDING INFORMATION MANAGEMENT (BIM) IMPLEMENTATION IN NAVAL CONSTRUCTION". The University Texas at El Paso, 1999. (2011)

13. Mehmet F. Hergunsel " BENEFITS OF BUILDING INFORMATION MODELING FOR CONSTRUCTION MANAGERS AND BIM BASED SCHEDULING".A Thesis Submitted to the Faulty of WORCESTER POLYTECHNIC INSTITUTE. (2011)

14. Mojtaba Taiebat, Tuning Up BIM for Safety Analysis-Proposing modeling logics for application of BIM in DfS. Doctor of Philosophy, e Virginia Polytechnic Institute and State University (2011), Retrieved from http://scholar.lib.vt.edu/these/available/etd12232011002222/unrestricted/Taiebat_M_D2011.pdf

15. McGraw-Hill Construction. Building Information Modeling: Transforming Design and Construction to Achieve Greater Industry
Productivity, McGraw-Hill Construction, New York. (2008)

16. Gambatese, J., Behm, M., Hinze, J. Viability of designing for construction worker safety. Journal of Construction Engineering and Management 131 (9), 1029-1036. (2005)

17. Chavada, R. and Dawood, N. N. 'An innovative approach to integrate $\mathrm{H} \& \mathrm{~S}$ issues in the construction project planning using serious game engine technologies', CONVR2010, Sendai, Japan, November 4-5, 2010, in Makanae, K., Yabuki, N. and Kashiyama, K. (eds) Proceedings of the 10th international conference on construction applications of virtual reality. CONVR2010 Organizing Committee, 209218 (2010)

18. Kiviniemi, A.. The effects of integrated BIM in processes and business models. Distributed Intelligence in Design, 125-135. (2011)

19. Kiviniemi, A., Tarandi, V., Karlshoj, J., Bell, H. and Karud, O.J. "Review of the development and implementation of IFC compatible BIM"(2008), Retrieved from www.eracobuild.eu/fileadmin/documents/Erabui ld_BIM_Final_Report_January_2008.pdf

20. Wong, A.K.D., Wong, F.K.W. and Nadeem, A. "Comparative roles of major stakeholders for the implementation of BIM in various countries", Proceedings of the International Conference on Changing Roles: New Roles, New Challenges, Noordwijk Aan Zee, The Building Information modelling 75 Netherlands, 5-9 October, (2009) Retrieved from www.changingroles09.nl/uploads/File/Final.KD. Wong-KW.Wong-Nadeem.pdf

21. Succar, B. "Building information modelling framework: a research and delivery foundation for industry stakeholders", Automation in Construction, 18, 357-75. (2009)

22. Khemlani, L, "CORENET e-plan check: Singapore's automated code checking system", AECbytes. (2005), Retrieved from www.aecbytes.com/buildingthefuture/2005/CO RENETePlanCheck.html

23. Arayici, Y., "Towards building information modelling for existing structures". Structural Survey, 26, (3), 210-22. (2008)

24. Hong Kong Construction Industry Council, Roadmap for Building Information Modelling Strategic Implementation in Hong Kong's Construction Industry. Construction Industry Council. (2014)

25. Malleson, A. Building Information ModelingWhat's going on in the world of BIM: NBS national BIM survey(2012). Retrieved from http://www.thenbs.com/topics/BIM/articles/what sGoingOnInWorldOfBIM.asp

26. Jernigan F. Big BIM little BIM: The Practical Approach to Building Information ModelingIntegrated Practice Done the Right Way! 2nd ed. 4Site Press (2007) 
27. Suermann P, Issa R. Evaluating industry perceptions of building information modeling (BIM) impact on construction, Journal of Information Technology in Construction (ITcon), 14, 574-594, (2009) Retrieved from http://www.itcon.org/2009/37

28. Zhang, J.P. and Hu, Z.Z. BIM- and 4D-based integrated solution of analysis and management for conflicts and structural safety problems during construction. Automation in Construction, 20, 155-166. (2011)

29. Zhang, S., Teizer, J., Lee, J. K., Eastman, C. M., and Venugopal, M. Building information modeling (BIM) and safety: Automatic safety checking of construction models and schedules. Automation in Construction, 29, 183-195. (2013) 